Cite this: Phys. Chem. Chem. Phys., 2013, 15, 20080

Received 28th April 2013, Accepted 22nd September 2013 DOI: $10.1039 / \mathrm{c} 3 \mathrm{cp} 51798 \mathrm{e}$

www.rsc.org/pccp

\title{
Benchmark calculations of metal carbonyl cations: relativistic vs. electron correlation effects
}

\author{
Eduard Matito, ${ }^{\text {ab }}$ Pedro Salvador ${ }^{a}$ and Jacek Styszyńskib
}

\begin{abstract}
In this paper we present benchmark results for isoelectronic metal carbonyl complexes of the groups 11 and 12 of the periodic table. The focus is on the geometry, vibrational frequencies, bond dissociation energy and chemical bonding. The description of these complexes requires a good balance between electron correlation and relativistic effects. Our results demonstrate that the combination of the effective core potential and the MP2 method gives quantitative results for the first- and the second-row transition metal complexes and only qualitative agreement for the third-row complexes. In order to obtain quantitative results for the whole series the use of four-component or X2C methods is mandatory. The fourth-row transition metal carbonyl complexes from groups 11 and 12 have been studied for the first time. The metal-carbon bond strength pattern along the group is shown to be highly dependent on the correct description of the relativistic effects. Finally, the relativistic effects on the bonding are studied by means of electron density difference maps, the analysis of the bond critical points of the electron density and the mechanism for $\sigma$-donation and $\pi$-backdonation. Our analysis indicates that the fourth-row complexes exhibit a strong covalent character induced by relativistic effects.
\end{abstract}

\section{Introduction}

The chemistry of metal carbonyl cations is an area of intensive investigation for both theoreticians and experimentalists. ${ }^{1-5}$ Some of the group 11 and group 12 transition metal (TM) complexes that were unknown or considered to be unstable to exist in the condensed phase were isolated as salts of weakly coordinating anions in the last decade of the 20th century. ${ }^{1,6-9}$ It is well known that the bonding between the TM atom $\mathrm{M}$ and the $\mathrm{CO}$ molecule has double-bond character due to the so-called $\sigma$-donation of the electron charge from the HOMO of carbon monoxide to the $\mathrm{d}(\sigma)$-orbital of the metal atom, and $\pi$-backdonation of the electron charge from the $\mathrm{d}(\pi)$ orbital to the LUMO of carbon monoxide; this model is known as Dewar-Chatt-Duncanson (DCD). ${ }^{10,11}$ This bonding mechanism has synergistic character: the transfer of the electron charge from the CO molecule to the TM ( $\sigma$-donation) will strengthen the bonding in carbon monoxide and the stretching frequency of $\mathrm{CO}$ will increase, while the transfer of electron charge from the metal atom to the $\mathrm{CO}$ molecule ( $\pi^{*}$-backdonation) will weaken the $\mathrm{CO}$ bond and the stretching frequency of the $\mathrm{CO}$ moiety will decrease. While the bonding mechanism is well known for the first rows of the periodic table, to our knowledge there are no

\footnotetext{
${ }^{a}$ Institut de Quimica Computacional i Catàlisi and Departament de Química, Universitat de Girona, Campus de Montilivi s/n, 17071 Girona, Catalonia, Spain. E-mail: ematito@gmail.com, perico@stark.udg.edu

${ }^{b}$ Institute of Physics, University of Szczecin, Wielkopolska 15, 70-451 Szczecin,

Poland.E-mail: jstysz@wmf.univ.szczecin.pl
}

studies on fourth-row TM complexes and very little has been said about the relativistic effects in these molecules.

The bonding between TM atoms and $\mathrm{CO}$ is of particular interest to model the chemisorption of $\mathrm{CO}$ onto metal films. There is an extensive literature on metal carbonyl species, see for instance ref. 12. Thus far, studies on metal carbonyls included at most TM from the third row of the periodic table. In this work we include the study of two molecules containing the superheavy elements roentgenium $(\mathrm{Rg})$ and copernicium $(\mathrm{Cn})$. One would expect the relativistic effects on $\mathrm{RgCO}^{+}$and $\mathrm{CnCO}^{2+}$ to be relevant. In particular, the strong relativistic contraction of the $7 \mathrm{~s}$ shell at the end of the transactinide series makes the $6 \mathrm{~d}$ electrons chemically active. ${ }^{13}$ Highly accurate calculations of Eliav et al. indicate that the ground state of the $\mathrm{Rg}^{+}$cation is $6 \mathrm{~d}^{8} 7 \mathrm{~s}^{2},{ }^{14}$ whereas in $\mathrm{Cn}^{2+}$ the results were not conclusive. ${ }^{15}$ On the other hand, $\mathrm{Rg}$ is expected to exhibit similar chemistry to other members of the group $11 .^{16}$

The aim of our paper is twofold: (i) first we will produce data of benchmark quality for series of group 11 and 12 metal monocarbonyl complexes $\left[\mathrm{M}(\mathrm{CO})^{+}\left(\mathrm{M}^{+}=\mathrm{Cu}^{+}, \mathrm{Ag}^{+}, \mathrm{Au}^{+}\right.\right.$and $\left.\mathrm{Rg}^{+}\right)$and $\mathrm{M}(\mathrm{CO})^{2+}\left(\mathrm{M}^{2+}=\mathrm{Zn}^{2+}, \mathrm{Cd}^{2+}, \mathrm{Hg}^{2+}\right.$ and $\left.\left.\mathrm{Cn}^{2+}\right)\right]$ with full inclusion of relativistic effects on the geometry and spectroscopic constants, (ii) we will analyze the relativistic effects on these properties and on the chemical bonding.

\section{Computational details}

It is well established that $\mathrm{M}-\mathrm{CO}$ needs an extensive treatment of electron correlation effects and, simultaneously, as the size 
of the TM grows, the relativistic corrections become of utmost importance. Therefore, we have performed highly accurate relativistic $\operatorname{CCSD}(\mathrm{T})$ calculations that we will compare against more approximate methods. The relativistic calculations reported in this paper use the Dirac-Coulomb (DC) Hamiltonian. ${ }^{17}$ The eigenvalue problem of this Hamiltonian can be reduced to the solution of the so-called Dirac-Fock equations, ${ }^{18}$ which are relativistic 4-component analogues of the well-known HartreeFock equations for many-electron systems. In the present study we have used the following relativistic four-component methods: Dirac-Fock (DF), the second order Møller-Plesset theory (MP2) and the coupled cluster with single and double substitutions perturbatively corrected for the effect of triple excitations $(\mathrm{CCSD}(\mathrm{T}))$. In addition, we have also performed two-component calculations using $\mathrm{X} 2 \mathrm{C},{ }^{19}$ which provides one of the most accurate two-component energy approximations available in the literature. ${ }^{20}$ In this manuscript, X2C approximation will be used for the first time to compute vibrational frequencies. We have also performed nonrelativistic calculations using the Lévy-Leblond Hamiltonian in order to estimate the relativistic effects on these molecular systems. $^{21}$ All these calculations have been performed using the DIRAC package of programs. ${ }^{22}$ For the transition metal atoms we have used the Dyall VTZ basis sets, ${ }^{23-26}$ while for $\mathrm{C}$ and $\mathrm{O}$ we have employed the cc-pVTZ basis sets of Dunning. ${ }^{27}$ In all these calculations we have used uncontracted basis sets. The atomic energies obtained with these basis sets are in good agreement with the corresponding numerical Dirac-Fock (DF) values of Visscher and Dyall. ${ }^{28}$ We have employed a Gaussian nuclear model in both nonrelativistic (Lévy-Leblond) and relativistic calculations. In the correlated calculations $[\mathrm{MP} 2$ and $\operatorname{CCSD}(\mathrm{T})]$ we have correlated the 26 valence electrons. The speed of light was taken to be 137.0359998 a.u. All atomic and most of the molecular calculations have been performed using $C_{2 \mathrm{v}}$ symmetry.

In addition, we also performed calculations using the typical computational-chemistry approach to study transition metals, i.e., the approximation of relativistic effects by the use of effective core potentials (ECP). This way, we can compare the performance of this standard approach against our benchmark calculations, which include the exact relativistic effects through Dirac's equation. The ECP calculations were performed for the same set of molecules using Dunning's cc-pVTZ basis set ${ }^{27}$ for carbon and oxygen and Stuttgart/Dresden ECP (SDD) for the electrons in closed-shells of the TMs, as implemented by default in Gaussian09. ${ }^{29}$ Specifically, $\mathrm{Cu}$ and $\mathrm{Zn}$ use the ECP10MDF pseudopotential, ${ }^{30} \mathrm{Ag}$ and $\mathrm{Cd}$ use ECP28MWB ${ }^{31}$ whereas Au and $\mathrm{Hg}$ use ECP60MWB. ${ }^{31}$ The valence electrons were treated with the basis sets supplemented in the original references. $^{30,31}$ These calculations use the point nucleus model and were performed with Gaussian09. ${ }^{29}$

The Dirac program $\uparrow$ is not capable of performing analytic geometry optimizations and harmonic frequency analysis for four-component methods. In this work numerical first and second derivatives of the energy with respect to nuclear

† Note that these calculations were performed with Dirac08, Dirac10 and Dirac11 programs. The last release of this program (Dirac12) includes analytical gradients but only at the DFT level. coordinates were computed using a finite difference approach. Our own generic code, which can serve as a driver of any electronic structure external program, was adapted to perform geometry optimizations and harmonic frequency calculations. A parallel version of this driver (DIRACcpp) calls the Dirac08 program to obtain the necessary single-point total energies at different geometries to calculate either the gradient or the Hessian matrix, upon request.

For the location of the minimum-energy geometries the driver uses a variable metric optimization algorithm, which combines Pulay's direct inversion in the iterative subspace (DIIS) with the Broyden-Fletcher-Goldfarb-Shanno (BFGS) updating procedure for the inverse Hessian in internal coordinates. $^{32}$

The second derivates in mass-weighted Cartesian coordinates can also be calculated numerically at the minimum energy structures with the driver, from which harmonic frequency calculations are readily obtained. For the particular case of a linear ABC system the program implements an alternative strategy that permits the calculation of the harmonic frequencies using only 9 single-point energy calculations. For linear molecules, the Hessian matrix in mass-weighted coordinates has five zero eigenvalues, whose eigenvectors describe the translation and rotation of the molecular framework. The analytical form of such eigenvectors can be deduced from the Eckart conditions if one assumes that the associated eigenvalues are exactly zero. We have found that if the minimum energy structure is optimized with a sufficiently tight criterion for the gradient, the error introduced with this assumption is negligible. Once the five eigenvectors are known, the analytical form of the remaining four eigenvectors can be deduced from group theory considerations and orthogonality constraints with the previous five eigenvectors. Thus, since on the basis of eigenvectors the Hessian matrix is diagonal, one can directly compute the numerical second derivatives using these coordinates, which readily correspond to the harmonic frequencies.

Both in geometry optimization and frequency four-component calculations we have assumed that the interatomic SS-integrals contribution can be approximated by the classical repulsion of small component atomic charges. ${ }^{33}$ During the geometry optimization process and vibrational frequency calculations, all spinors with energy lower than 3 a.u. were included in the virtual space. However, the single-point calculations required to obtain the bond dissociation energy $\left[D_{\mathrm{e}}\left(\mathrm{M}^{n+}-\mathrm{CO}\right)\right]$ were performed including molecular spinors with an energy $\varepsilon$ smaller than 30 a.u.

The total electron density was calculated on a cubic grid of eight million points (200 points per side, step size 0.06 or smaller). The $\mathrm{MCO}^{n+}$ linear species present two local minima of the electron density along the $Z$-axis corresponding to the bond critical points (BCPs) ${ }^{34}$ of $\mathrm{M}-\mathrm{C}$ and $\mathrm{C}-\mathrm{O}$ bonds. These BCPs were located by finding the minimum of the fourth-order polynomial interpolated with the five nearest neighbors of the grid point with a minimum density value between $\mathrm{M}-\mathrm{C}$ and $\mathrm{C}-\mathrm{O}$ atoms. Our results were contrasted using a modified version of Prof. Scherer's software $^{35}$ to treat cube files. 


\section{Results and discussion}

We have investigated two series of $\mathrm{d}^{10}$ metal monocarbonyl cations: $\mathrm{M}(\mathrm{CO})^{+}(\mathrm{M}=\mathrm{Cu}, \mathrm{Ag}, \mathrm{Au}$ and $\mathrm{Rg})$ and $\mathrm{M}(\mathrm{CO})^{2+}(\mathrm{M}=\mathrm{Zn}$, $\mathrm{Cd}, \mathrm{Hg}$ and $\mathrm{Cn}$ ) in their singlet ground state. The bond lengths, vibrational frequencies and bond dissociation energies (into singlet $\mathrm{M}^{+} / \mathrm{M}^{2+}$ and $\mathrm{CO}$ moieties) using different computational methods are collected in Tables 1 and 2. Our ECP-MP2 results are very close to those reported by Lupinetti et al. ${ }^{3}$ using the same ECP and a smaller basis set for the CO fragment. The Dirac-Fock (DF) results are included in order to assess the electron correlation effects on the properties studied, while Lévy-Leblond (LL) calculations are included to estimate the

Table 1 Bond lengths (in $\AA$ ), vibrational frequencies $\left(\mathrm{cm}^{-1}\right)$ and bond dissociation energies $\left(\mathrm{kcal} \mathrm{mol}^{-1}\right)$ of the $\mathrm{M}(\mathrm{CO})^{+} \mathrm{molecules}\left(\mathrm{M}^{+}=\mathrm{Cu}^{+}, \mathrm{Ag}^{+}, \mathrm{Au}^{+}\right.$and $\left.\mathrm{Rg}^{+}\right)$ obtained using relativistic (DC), two-component methods (X2C), nonrelativistic Lévy-Leblond (LL) and effective core potential (ECP) methods

\begin{tabular}{|c|c|c|c|c|c|c|c|c|}
\hline System & & Method & $R_{1}\left(\mathrm{M}^{+}-\mathrm{C}\right)$ & $R_{2}(\mathrm{C}-\mathrm{O})$ & $\nu\left(\mathbf{M}^{+}-\mathrm{C}\right)$ & $\nu(\mathrm{C}-\mathrm{O})$ & $\nu_{\text {bend }}$ & $D_{\mathrm{e}}\left(\mathrm{M}^{+}-\mathrm{CO}\right)$ \\
\hline \multirow[t]{13}{*}{$\mathrm{CuCO}^{+}$} & \multirow[t]{3}{*}{$\mathrm{DC}$} & $\mathrm{DF}$ & 2.120 & 1.091 & 234 & 2550 & 261 & 18.0 \\
\hline & & MP2 & 1.808 & 1.130 & 353 & 2179 & 323 & 43.9 \\
\hline & & $\operatorname{CCSD}(\mathrm{T})$ & 1.877 & 1.123 & 366 & 2252 & 289 & 37.3 \\
\hline & \multirow[t]{3}{*}{ LL } & $\mathrm{DF}$ & 2.171 & 1.091 & 220 & 2547 & 250 & 16.5 \\
\hline & & MP2 & 1.861 & 1.133 & 397 & 2184 & 303 & 38.9 \\
\hline & & $\operatorname{CCSD}(\mathrm{T})$ & 1.904 & 1.128 & 336 & 2252 & 272 & 33.3 \\
\hline & \multirow[t]{3}{*}{$\mathrm{X} 2 \mathrm{C}$} & $\mathrm{DF}$ & 2.121 & 1.091 & 234 & 2550 & 261 & 18.0 \\
\hline & & MP2 & 1.809 & 1.130 & 419 & 2180 & 323 & 44.0 \\
\hline & & $\operatorname{CCSD}(\mathrm{T})$ & 1.878 & 1.124 & 367 & 2252 & 289 & 37.4 \\
\hline & \multirow[t]{4}{*}{ ECP } & B3LYP & 1.874 & 1.115 & 376 & 2312 & 292 & 40.7 \\
\hline & & MP2 & 1.849 & 1.130 & 375 & 2186 & 306 & 38.8 \\
\hline & & CCSD & 1.943 & 1.116 & 322 & 2338 & 280 & 31.0 \\
\hline & & Expt. & - & - & - & $2234^{a}$ & - & $36^{b}$ \\
\hline \multirow[t]{13}{*}{$\mathrm{AgCO}^{+}$} & \multirow[t]{3}{*}{$\mathrm{DC}$} & $\mathrm{DF}$ & 2.433 & 1.092 & 163 & 2531 & 214 & 11.6 \\
\hline & & MP2 & 2.092 & 1.133 & 315 & 2185 & 315 & 28.7 \\
\hline & & $\operatorname{CCSD}(\mathrm{T})$ & 2.137 & 1.128 & 300 & 2242 & 249 & 25.0 \\
\hline & \multirow[t]{3}{*}{$\mathrm{LL}$} & $\mathrm{DF}$ & 2.561 & 1.094 & 145 & 2522 & 197 & 9.7 \\
\hline & & MP2 & 2.197 & 1.134 & 289 & 2185 & 287 & 22.0 \\
\hline & & $\operatorname{CCSD}(\mathrm{T})$ & 2.237 & 1.129 & 278 & 2239 & 276 & 19.4 \\
\hline & \multirow[t]{3}{*}{$\mathrm{X} 2 \mathrm{C}$} & $\mathrm{DF}$ & 2.434 & 1.092 & 163 & 2531 & 214 & 11.6 \\
\hline & & MP2 & 2.093 & 1.133 & 316 & 2181 & 314 & 28.7 \\
\hline & & $\operatorname{CCSD}(\mathrm{T})$ & 2.138 & 1.128 & 300 & 2242 & 294 & 25.0 \\
\hline & \multirow[t]{4}{*}{ ECP } & B3LYP & 2.155 & 1.115 & 261 & 2311 & 227 & 26.3 \\
\hline & & MP2 & 2.182 & 1.129 & 228 & 2187 & 228 & 22.6 \\
\hline & & CCSD & 2.226 & 1.117 & 217 & 2323 & 225 & 21.0 \\
\hline & & Expt. & 2.100 & - & - & $2233^{c}$ & - & $21^{b}$ \\
\hline \multirow[t]{13}{*}{$\mathrm{AuCO}^{+}$} & \multirow[t]{3}{*}{ DC } & DF & 2.101 & 1.089 & 265 & 2556 & 300 & 22.6 \\
\hline & & MP2 & 1.858 & 1.136 & 489 & 2182 & 381 & 59.5 \\
\hline & & $\operatorname{CCSD}(\mathrm{T})$ & 1.907 & 1.130 & 425 & 2236 & 351 & 51.1 \\
\hline & \multirow[t]{3}{*}{ LL } & $\mathrm{DF}$ & 2.666 & 1.094 & 128 & 2516 & 186 & 8.5 \\
\hline & & MP2 & 2.288 & 1.133 & 250 & 2185 & 191 & 20.7 \\
\hline & & $\operatorname{CCSD}(\mathrm{T})$ & 2.328 & 1.129 & 232 & 2236 & 219 & 18.2 \\
\hline & \multirow[t]{3}{*}{$\mathrm{X} 2 \mathrm{C}$} & $\mathrm{DF}$ & 2.102 & 1.089 & 266 & 2556 & 299 & 22.6 \\
\hline & & MP2 & 1.860 & 1.136 & 471 & 2177 & 372 & 59.3 \\
\hline & & $\operatorname{CCSD}(\mathrm{T})$ & 1.908 & 1.130 & 426 & 2235 & 348 & 51.0 \\
\hline & \multirow[t]{4}{*}{ ECP } & B3LYP & 1.955 & 1.116 & 384 & 2306 & 309 & 47.7 \\
\hline & & MP2 & 1.899 & 1.131 & 400 & 2186 & 328 & 46.1 \\
\hline & & CCSD & 1.935 & 1.117 & 371 & 2333 & 323 & 41.0 \\
\hline & & Expt. & - & - & - & $2237^{c}$ & - & \\
\hline \multirow[t]{9}{*}{$\mathrm{RgCO}^{+}$} & \multirow[t]{3}{*}{ DC } & DF & 1.848 & 1.092 & 555 & 2530 & 475 & 119.6 \\
\hline & & MP2 & 1.798 & 1.146 & 677 & 2157 & 492 & 178.9 \\
\hline & & $\operatorname{CCSD}(\mathrm{T})$ & 1.830 & 1.138 & 591 & 2202 & 454 & 130.8 \\
\hline & \multirow[t]{3}{*}{ LL } & $\mathrm{DF}$ & 2.977 & 1.096 & 101 & 2499 & 161 & 5.8 \\
\hline & & MP2 & 2.478 & 1.134 & 221 & 2157 & 329 & 13.7 \\
\hline & & $\operatorname{CCSD}(\mathrm{T})$ & 2.517 & 1.130 & 210 & 2230 & 162 & 12.1 \\
\hline & \multirow[t]{3}{*}{$\mathrm{X} 2 \mathrm{C}$} & $\mathrm{DF}$ & 1.856 & 1.092 & 540 & 2528 & 470 & 118.3 \\
\hline & & MP2 & 1.802 & 1.145 & 594 & 2147 & 417 & 177.5 \\
\hline & & $\operatorname{CCSD}(\mathrm{T})$ & 1.836 & 1.138 & 580 & 2197 & 443 & 126.8 \\
\hline
\end{tabular}

${ }^{a}$ From ref. 36. ${ }^{b}$ From ref. 7. ${ }^{c}$ From ref. 50. 
Table 2 Bond lengths $(\AA \AA)$, vibrational frequencies $\left(\mathrm{cm}^{-1}\right)$ and bond dissociation energies $\left(\mathrm{kcal} \mathrm{mol}^{-1}\right)$ of the $\mathrm{M}(\mathrm{CO})^{2+}$ molecules $\left(\mathrm{M}^{2+}=\mathrm{Zn}^{2+}, \mathrm{Cd}^{2+}, \mathrm{Hg}^{2+}\right.$ and $\left.\mathrm{Cn}^{2+}\right)$ obtained using relativistic (DC), two-component methods (X2C), nonrelativistic Lévy-Leblond (LL) and effective core potential methods (ECP)

\begin{tabular}{|c|c|c|c|c|c|c|c|c|}
\hline System & & Method & $R\left(\mathrm{M}^{2+}-\mathrm{C}\right)$ & $R(\mathrm{C}-\mathrm{O})$ & $\nu\left(\mathbf{M}^{2+}-\mathrm{C}\right)$ & $\nu(\mathrm{C}-\mathrm{O})$ & $\nu_{\text {bend }}$ & $D_{\mathrm{e}}\left(\mathrm{M}^{2+}-\mathrm{CO}\right)$ \\
\hline \multirow[t]{12}{*}{$\mathrm{ZnCO}^{2+}$} & \multirow[t]{3}{*}{ DC } & $\mathrm{DF}$ & 2.085 & 1.081 & 356 & 2650 & 314 & 60.2 \\
\hline & & MP2 & 1.999 & 1.129 & 389 & 2201 & 265 & 82.5 \\
\hline & & $\operatorname{CCSD}(\mathrm{T})$ & 2.024 & 1.122 & 374 & 2298 & 263 & 78.8 \\
\hline & \multirow[t]{3}{*}{ LL } & DF & 2.107 & 1.082 & 348 & 2646 & 311 & 57.7 \\
\hline & & MP2 & 2.024 & 1.130 & 380 & 2201 & 269 & 78.4 \\
\hline & & $\operatorname{CCSD}(\mathrm{T})$ & 2.047 & 1.122 & 367 & 2296 & 272 & 75.0 \\
\hline & \multirow[t]{3}{*}{$\mathrm{X} 2 \mathrm{C}$} & DF & 2.085 & 1.081 & 356 & 2650 & 314 & 60.2 \\
\hline & & MP2 & 2.000 & 1.129 & 388 & 2201 & 265 & 82.4 \\
\hline & & $\operatorname{CCSD}(\mathrm{T})$ & 2.024 & 1.122 & 374 & 2298 & 269 & 78.8 \\
\hline & \multirow[t]{3}{*}{ ECP } & B3LYP & 2.018 & 1.106 & 363 & 2391 & 295 & 85.0 \\
\hline & & MP2 & 1.995 & 1.126 & 391 & 2205 & 295 & 77.9 \\
\hline & & CCSD & 2.023 & 1.110 & 379 & 2393 & 297 & 72.5 \\
\hline \multirow[t]{12}{*}{$\mathrm{CdCO}^{2+}$} & \multirow[t]{3}{*}{ DC } & DF & 2.312 & 1.083 & 283 & 2625 & 283 & 43.1 \\
\hline & & MP2 & 2.173 & 1.130 & 341 & 2201 & 298 & 64.5 \\
\hline & & $\operatorname{CCSD}(\mathrm{T})$ & 2.202 & 1.123 & 344 & 2286 & 295 & 61.1 \\
\hline & \multirow[t]{3}{*}{ LL } & DF & 2.376 & 1.084 & 267 & 2616 & 273 & 38.6 \\
\hline & & MP2 & 2.241 & 1.130 & 311 & 2200 & 292 & 56.6 \\
\hline & & $\operatorname{CCSD}(\mathrm{T})$ & 2.257 & 1.124 & 334 & 2284 & 290 & 53.6 \\
\hline & \multirow[t]{3}{*}{$\mathrm{X} 2 \mathrm{C}$} & DF & 2.311 & 1.083 & 284 & 2625 & 283 & 43.1 \\
\hline & & MP2 & 2.173 & 1.130 & 341 & 2201 & 376 & 64.4 \\
\hline & & $\operatorname{CCSD}(\mathrm{T})$ & 2.202 & 1.123 & 344 & 2286 & 304 & 61.1 \\
\hline & \multirow[t]{3}{*}{ ECP } & B3LYP & 2.233 & 1.108 & 296 & 2375 & 265 & 64.0 \\
\hline & & MP2 & 2.235 & 1.127 & 304 & 2198 & 264 & 56.2 \\
\hline & & CCSD & 2.252 & 1.111 & 298 & 2375 & 268 & 53.0 \\
\hline \multirow[t]{12}{*}{$\mathrm{HgCO}^{2+}$} & \multirow[t]{3}{*}{ DC } & DF & 2.211 & 1.081 & 303 & 2645 & 305 & 53.9 \\
\hline & & MP2 & 2.060 & 1.130 & 380 & 2194 & 373 & 86.8 \\
\hline & & $\operatorname{CCSD}(\mathrm{T})$ & 2.110 & 1.122 & 330 & 2290 & 276 & 81.6 \\
\hline & \multirow[t]{3}{*}{ LL } & DF & 2.474 & 1.085 & 239 & 2607 & 261 & 33.8 \\
\hline & & MP2 & 2.321 & 1.131 & 310 & 2195 & 347 & 51.5 \\
\hline & & $\operatorname{CCSD}(\mathrm{T})$ & 2.363 & 1.124 & 292 & 2285 & 236 & 48.7 \\
\hline & \multirow[t]{3}{*}{$\mathrm{X} 2 \mathrm{C}$} & DF & 2.212 & 1.081 & 302 & 2645 & 305 & 53.9 \\
\hline & & MP2 & 2.062 & 1.130 & 364 & 2191 & 320 & 86.5 \\
\hline & & $\operatorname{CCSD}(\mathrm{T})$ & 2.111 & 1.122 & 338 & 2290 & 275 & 81.4 \\
\hline & \multirow[t]{3}{*}{ ECP } & B3LYP & 2.149 & 1.107 & 312 & 2384 & 284 & 82.2 \\
\hline & & MP2 & 2.116 & 1.126 & 324 & 2202 & 286 & 72.3 \\
\hline & & CCSD & 2.139 & 1.110 & 315 & 2388 & 289 & 68.3 \\
\hline \multirow[t]{9}{*}{$\mathrm{CnCO}^{2+}$} & \multirow[t]{3}{*}{ DC } & DF & 1.922 & 1.078 & 514 & 2684 & 416 & 135.5 \\
\hline & & MP2 & 1.867 & 1.136 & 567 & 2183 & 410 & 196.1 \\
\hline & & $\operatorname{CCSD}(\mathrm{T})$ & 1.902 & 1.126 & 524 & 2282 & 402 & 173.9 \\
\hline & \multirow[t]{3}{*}{ LL } & DF & 2.697 & 1.087 & 198 & 2584 & 236 & 24.8 \\
\hline & & MP2 & 2.465 & 1.131 & 275 & 2193 & 222 & 39.3 \\
\hline & & $\operatorname{CCSD}(\mathrm{T})$ & 2.495 & 1.125 & 266 & 2272 & 233 & 36.9 \\
\hline & \multirow[t]{3}{*}{$\mathrm{X} 2 \mathrm{C}$} & DF & 1.929 & 1.078 & 507 & 2683 & 414 & 134.1 \\
\hline & & MP2 & 1.871 & 1.136 & 566 & 2180 & 362 & 194.4 \\
\hline & & $\operatorname{CCSD}(\mathrm{T})$ & 1.907 & 1.126 & 519 & 2279 & 404 & 172.0 \\
\hline
\end{tabular}

relativistic effects by comparison with four-component DiracCoulomb results (DC).

First of all, let us examine both effects on the ground state structures of our molecular set. All the molecules studied are linear and the molecular geometry is thus fully determined by the $\mathrm{C}-\mathrm{O}$ and the metal-carbon $(\mathrm{M}-\mathrm{C})$ distances. The $\mathrm{C}-\mathrm{O}$ distance slightly increases upon inclusion of electron correlation as we can see by comparing the results obtained at MP2 and DF levels. The MP2 method tends to overestimate the electron correlation and the $\mathrm{C}-\mathrm{O}$ distances obtained at the $\operatorname{CCSD}(\mathrm{T})$ level are systematically slightly shorter. The C-O distance slightly increases going down the group, particularly for the superheavy elements. Also, the $\mathrm{C}-\mathrm{O}$ distance is always shorter for the more positively charged species (group 12) as one can observe by comparison of the complexes with TMs in the same period. These results indicate that the $\pi$-backdonation mechanism is more favorable for the larger metal atoms, and especially when its effective charge is smaller. These trends are observed both for the four-component and the Lévy-Leblond calculations, which manifest that the $\mathrm{C}-\mathrm{O}$ distance is not significantly affected by relativistic effects.

On the other hand, the $\mathrm{M}-\mathrm{C}$ distances are strongly influenced by both electron correlation and relativistic effects. The latter can be easily visualized in Fig. 1, where the difference between 


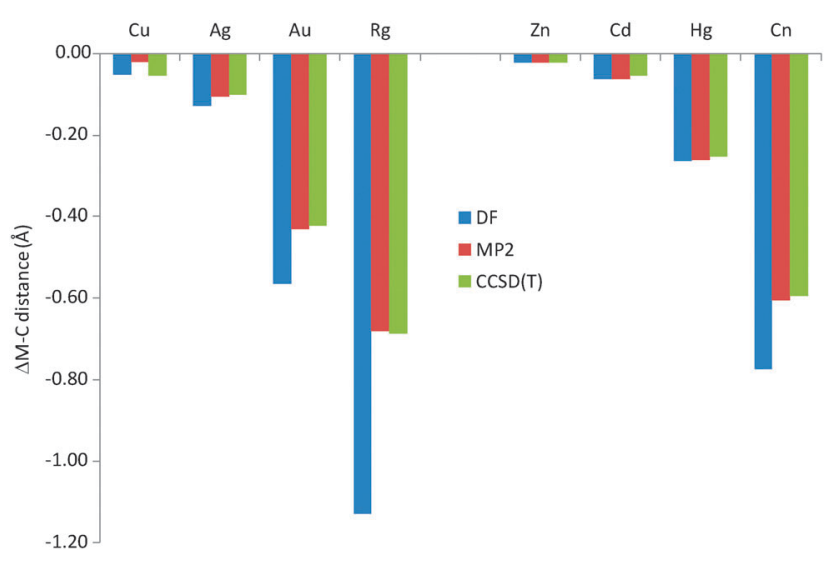

Fig. 1 Difference between $D C$ and $L L$ optimized $M-C$ distances for different levels of theory.

the DC and LL optimized M-C distances is represented for the different levels of theory and species studied. In all cases, the $\mathrm{M}-\mathrm{C}$ distance decreases upon consideration of relativistic corrections. Such a decrease is similar for both MP2 and $\operatorname{CCSD}(\mathrm{T})$ methods, and systematically larger when no electron correlation is included (DF). As expected, the relativistic effects are more important going down the group and for the first-row compounds $\mathrm{CuCO}^{+}$and $\mathrm{ZnCO}^{2+}$ the decrease of the $\mathrm{M}-\mathrm{C}$ distance is only ca. 0.05 and $0.02 \AA$, respectively.

In the case of $\mathrm{AgCO}^{+}$the effect is already of the order of $0.1 \AA$. In fact, quantitative agreement with the experimental $\mathrm{Ag}-\mathrm{C}$ distance is only achieved using a DC calculation that includes electron correlation (0.01-0.04 $\AA$ deviation). The approximate inclusion of relativistic effects by the use of ECPs insufficiently improves the LL results. However, incidentally, the combination of B3LYP and ECP yields an $\mathrm{Ag}-\mathrm{C}$ distance quite close to our best theoretical estimate.

The comparison of molecules with TMs of the first to the third rows reveals that the relativistic effect upon the $\mathrm{M}-\mathrm{C}$ distance is smaller for the more positively charged species by roughly a factor of two. For the two fourth-row metals the relativistic corrections are more similar but huge (about $0.6 \AA$ for MP2 and $\operatorname{CCSD}(\mathrm{T})$ methods and up to $1.2 \AA$ for $\mathrm{DF}$ ). The superheavy element ( $\mathrm{Rg}$ and $\mathrm{Cn}$ ) carbonyl complexes are, to the best of our knowledge, studied for the first time in this work. Thus, there are neither ECPs available for these elements nor experimental data to compare with.

The electron correlation effects upon the $\mathrm{M}-\mathrm{C}$ distances are also relevant, as depicted in Fig. 2. When going from DF to MP2, the M-C distance is significantly decreased. Similarly to the $\mathrm{C}-\mathrm{O}$ distance, MP2 overcorrects the electron correlation effects. Thus, going from MP2 to $\operatorname{CCSD}(\mathrm{T})$ one can observe a minor increase (up to $0.05 \AA$ ) of the $\mathrm{M}-\mathrm{C}$ distance in all cases.

For the first- and second-row compounds the electron correlation effects upon the $\mathrm{M}-\mathrm{C}$ distance are much larger than the relativistic corrections themselves. They are particularly large in the case of $\mathrm{CuCO}^{+}$and $\mathrm{AgCO}^{+}$systems, with corrections of $c a .0 .3 \AA$. For the isoelectronic species, $\mathrm{ZnCO}^{2+}$ and $\mathrm{CdCO}^{2+}$, the change upon the $\mathrm{M}-\mathrm{C}$ distance is smaller by roughly a factor of 3 .

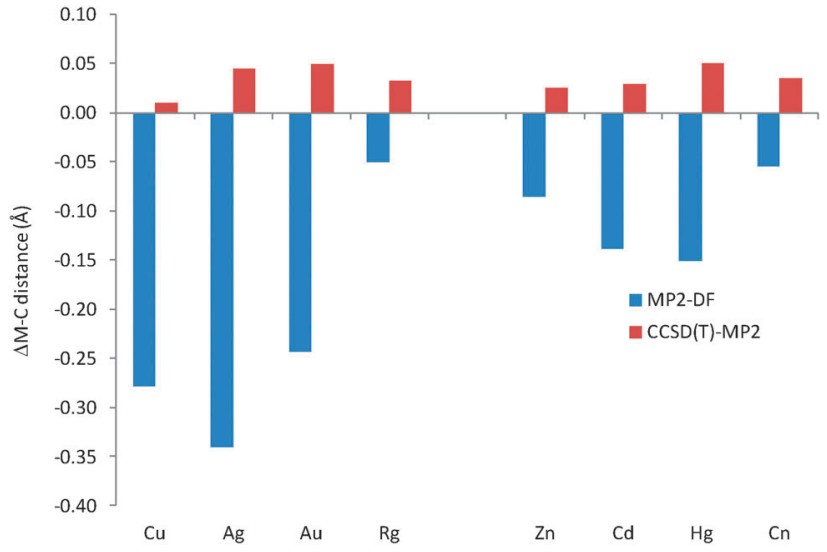

Fig. 2 Electron correlation effect upon the optimized $\mathrm{M}-\mathrm{C}$ distance (using fourcomponent calculations). The figure collects the difference between CCSD(T) and DF values, in red, and the difference between MP2 and DF values, in blue.

Both the inclusion of electron correlation and the relativistic correction tend to decrease the $\mathrm{M}-\mathrm{C}$ distance. Hence, no cancellation occurs and both effects must be taken into account in the calculations when they are both significant. This is clearly the case of the third-row compounds like $\mathrm{AuCO}^{+}$. For this system the $\mathrm{M}-\mathrm{C}$ distance calculated at the simplest LL-DF level of theory is $2.67 \AA$, whereas the best theoretical estimate, DC-CCSD(T), yields $1.91 \AA$. This $0.7 \AA$ difference in the $\mathrm{M}-\mathrm{C}$ distance equally originates from both electron correlation and relativistic effects. The approximate relativistic corrections using ECPs work very well for $\mathrm{AuCO}^{+}$and $\mathrm{HgCO}^{2+}$ species. The $\mathrm{M}-\mathrm{C}$ distances are within $0.05 \AA$ for all methods applied.

Curiously, the correlation effects decrease significantly in the case of the superheavy elements. The MP2 correction is roughly cancelled when going to $\mathrm{CCSD}(\mathrm{T})$, so the DC-DF results are very similar to the best theoretical estimates (as far as the $\mathrm{M}-\mathrm{C}$ distance is concerned, see below). However, if no relativistic correction is included, the difference between CCSD(T) and DF M-C optimized distances is more than $0.4 \AA$. This is a clear manifestation of the nonadditive character of the two corrections. For these systems the relativistic corrections clearly dominate.

Let us now discuss the results obtained for the vibrational frequency analysis. Strong absorptions in the $\mathrm{C}-\mathrm{O}$ stretching vibrational region are expected for unsaturated transition-metal carbonyls. The shift of the C-O stretching frequency upon interaction with the TM atom is related to the extent of the $\sigma$-donation of $\mathrm{CO}$ and the $\pi$-backdonation of the TM. It is well known that the cationic $\mathrm{MCO}^{n+}$ complexes show larger stretching frequencies compared to the free $\mathrm{CO}$, due to the electrostatic $\mathrm{M}^{n+}$-CO bonding. The more charge on the metal atom the larger the shift in the $\mathrm{CO}$ frequency. On the other hand, the $\pi$-backdonation lowers the CO stretching frequency but to a lesser extent. The more external are the $\mathrm{d}$ orbitals of the atom the stronger is the $\pi$-backdonation. Thus, one would expect smaller CO stretching frequencies going down the group, and a minor effect in the case of more positively charged TM atoms.

Table 3 contains the optimized bond distances and harmonic frequencies of the CO molecule obtained using DF, MP2 and 
Table 3 Bond length (in $\AA$ ) and vibrational frequency (in $\mathrm{cm}^{-1}$ ) of the CO molecule obtained using relativistic and nonrelativistic (Lévy-Leblond) methods

\begin{tabular}{lll}
\hline Method & $R(\mathrm{C}-\mathrm{O})$ & $\nu(\mathrm{C}-\mathrm{O})$ \\
\hline DC-DF & 1.104 & 2420 \\
LL-DF & 1.104 & 2420 \\
DC-MP2 & 1.143 & 2113 \\
LL-MP2 & 1.143 & 2114 \\
DC-CCSD(T) & 1.141 & 2140 \\
LL-CCSD(T) & 1.141 & 2141 \\
Expt. & 1.128 & 2143 \\
\hline
\end{tabular}

$\operatorname{CCSD}(\mathrm{T})$ methods. As expected, the relativistic corrections are negligible for this light molecule. The highly accurate $\operatorname{CCSD}(\mathrm{T})$ method closely matches the experimental value of $2143 \mathrm{~cm}^{-1}$.

The vibrational frequencies for the $\mathrm{MCO}^{n+}$ species are collected in Tables 1 and 2. Relativistic effects do not significantly affect the CO stretching frequency, but its value is highly dependent on the amount of electron correlation introduced. The complexes of the group 11 have DC-CCSD(T) carbonyl stretching values close to $2240 \mathrm{~cm}^{-1}$ with the exception of $\mathrm{RgCO}^{+}$that has a somewhat smaller value of $2202 \mathrm{~cm}^{-1}$. The DC-CCSD(T) values are within $20 \mathrm{~cm}^{-1}$ compared to the experimental ones. The agreement is particularly impressive for $\mathrm{AuCO}^{+}\left(1 \mathrm{~cm}^{-1}\right.$ deviation). It is worth mentioning that in the case of $\mathrm{CuCO}^{+}$some authors ${ }^{3}$ have taken the $2178 \mathrm{~cm}^{-1}$ value reported by Rack et al. ${ }^{6}$ for the [CuCO][AsF $\left.{ }_{6}\right]$ system in the solid state as the experimental reference value. We prefer the more recent neon matrix gas-phase result from Zhou et al. ${ }^{36}$ of $2234 \mathrm{~cm}^{-1}$. The isoelectronic complexes with TM from the group 12 exhibit larger $\mathrm{CO}$ stretching values in the narrow range between 2282 and $2298 \mathrm{~cm}^{-1}$.

In Fig. 3, we depict the shift in the carbonyl frequency obtained for different methods with four-component calculations. The calculated shift is larger for the DF method and MP2 again overcorrects the electron correlation effects. The DF method, lacking any electron correlation, tends to overestimate the electrostatic interaction between the metal and the $\mathrm{CO}$ moiety, thus leading to a larger frequency shift. The frequency shift does not change importantly going down the group, which indicates that the $\pi$-backdonation

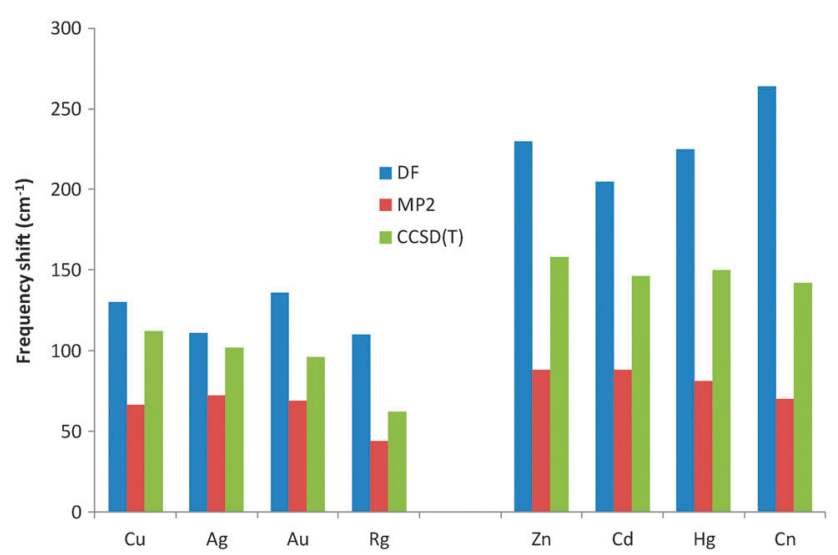

Fig. 3 Electron correlation effects upon the shift of the CO stretching frequency using four-component calculations. Frequency shifts are calculated for each method using the respective CO free value from Table 3. in these systems is rather weak. A relevant exception is the $\mathrm{RgCO}^{+}$species. The DC-CCSD(T) calculated shift is $62 \mathrm{~cm}^{-1}$, considerably smaller than $96 \mathrm{~cm}^{-1}$ obtained for $\mathrm{AuCO}^{+}$. This result could also be consistent with a weaker electrostatic interaction between the metal and the CO. However, the large bond dissociation energy as compared to that of $\mathrm{AuCO}^{+}$(see below) indicates that the reduction of the frequency shift is likely due to an enhanced $\pi$-backdonation.

The ECP-MP2 results provide CO frequencies in reasonable agreement with DC-CCSD(T) results. ECP-B3LYP and ECP-CCSD give very similar values, but both tend to overestimate the frequency by roughly $100 \mathrm{~cm}^{-1}$. $\neq$ We also applied the ECP-MP3 method to $\mathrm{CuCO}^{+}$and obtained a much worse value of $2433 \mathrm{~cm}^{-1}$. This opportune error cancellation in the ECP-MP2 combination also gives a pretty good estimate for the $\mathrm{CO}$ stretching frequency in $\mathrm{ZnCO}^{2+}$, but somewhat worse for third-row complexes, where the relativistic effects are more pronounced. ${ }^{38-40}$ Thus, we prefer to consider the DC-CCSD(T) value as the best theoretical estimate.

The metal-carbon stretching and bending frequencies are also sensitive to electron correlation but in this case the relativistic corrections play a significant role going down the group. For the third and especially fourth-row TMs the omission of relativistic effects leads to a major underestimation of the $\mathrm{M}-\mathrm{C}$ frequencies. Again, the ECP-MP2 combination provides reasonable values.

We have already seen that both electron correlation and relativistic corrections are responsible for the large contraction of the $\mathrm{M}-\mathrm{C}$ bond. The observed trends in the metal-carbon distances may be connected with the strength of the metal carbonyl bonding. Indeed, if no relativistic corrections are included (LL results) the bond dissociation energies decrease going down the group for all methods, and exhibit a good linear correlation $\left(r^{2}>0.83\right)$ with the $\mathrm{M}-\mathrm{C}$ bond lengths. This can be interpreted as a weakening of the bond. However, when the relativistic effects are properly included with the DC calculations the values do not show a linear correlation. When going from $\mathrm{AgCO}^{+}$to $\mathrm{RgCO}^{+}$, we observe the shortening of the bond accompanying the increase of both the dissociation energy and the MC stretching frequency. Such behavior, in turn, can be interpreted as the strengthening of the bond between the metal and the carbon atoms. A similar trend is observed for the group 12 metal carbonyl cations. On the other hand, the dissociation energies for the $\mathrm{MCO}^{2+}$ species are much higher than for the isoelectronic $\mathrm{MCO}^{+}$ones, highlighting the electrostatic character of the bonding interaction.

For the first- and second-row metals the $D_{\mathrm{e}}$ values calculated including electron correlation are in reasonable agreement with the available experimental results. The DF results clearly underestimate the binding energy. However, for the third-row metals and especially for the superheavy elements, the dissociation energies are highly underestimated if relativistic corrections are not properly included. In the case of $\mathrm{RgCO}^{+}$the computed $D_{\mathrm{e}}$ values

$\ddagger$ M. P. Johansson and P. Pyykkö recently published the CO stretching frequency of $\mathrm{AuCO}^{+}$at the $\operatorname{CCSD}(\mathrm{T}) /$ aug-cc-pV5Z(-PP) level using the relativistic 19-electron effective core potentials for gold, obtaining a result which is only $33 \mathrm{~cm}^{-1}$ off the experimental value. ${ }^{37}$ 
differ by an order of magnitude (see Table 1). Thus, due to relativistic effects, the bond dissociation energies increase significantly going down the group. Our 4C-CCSD(T) value for the $\mathrm{RgCO}^{+}$system amounts $130.8 \mathrm{kcal} \mathrm{mol}^{-1}$, almost three times larger than that for $\mathrm{AuCO}^{+}$. This value, put together with the substantial decrease of the $\mathrm{CO}$ vibrational frequency, suggests that the $\mathrm{M}-\mathrm{CO}$ bonding in the superheavy elements may have a significant covalent character, concomitant with relativistic effects. This explains why the bond dissociation energy in $\mathrm{RgCO}^{+}$would be much larger than for $\mathrm{CuCO}^{+}$, while the respective $\mathbf{M}-\mathbf{C}$ distances are very similar. However, it is worth noting that some studies indicate that the ground state of the $\mathrm{Rg}^{+}$, and particularly $\mathrm{Cn}^{2+}$ cations might be open-shell, depending on the level of theory and whether or not the relativistic effects are included. ${ }^{14,15}$ A thorough study of the plethora of open-shell states of these cations is out of the scope of this work. Thus, our reported $D_{\mathrm{e}}$ values correspond to the dissociation into singlet $\mathrm{Rg}^{+} / \mathrm{Cn}^{2+}$ and CO moieties. This allows for a better contrast of the trends of the relativistic corrections in combination with the gradual inclusion of electron correlation effects along the group. Clearly, our reported $D_{\mathrm{e}}$ values for these two systems might be overestimated.

It is worth comparing the values obtained using $\mathrm{X} 2 \mathrm{C}$, an approximate two-component method, with those obtained with four-component calculations. The agreement between X2C geometries and DC ones is excellent, as it also the case of dissociation energies. The CO vibrational frequencies obtained with $\mathrm{X} 2 \mathrm{C}$ also match very well the DC values. However, there are a few exceptions in the case of bending and $\mathrm{M}-\mathrm{C}$ stretching frequencies, which show deviations up to $80 \mathrm{~cm}^{-1}$ (see for instance $\mathrm{RgCO}^{+}$). Interestingly, these discrepancies show mostly for MP2 (five instances) and only once for $\operatorname{CCSD}(\mathrm{T})$, in the case of $\mathrm{AgCO}^{+}$.

Even though uncontracted basis sets of triple-zeta quality have been employed in the geometry optimization and frequency calculations, basis set incompleteness errors may still be significant in the calculation of dissociation energies with correlated calculations. First, we have evaluated the basis set superposition error (BSSE) effects upon the energetics, the geometry and harmonic frequencies in these systems using the counterpoise (CP) method $^{41}$ as implemented in Gaussian for the non-relativistic calculations. In the case of the ECP calculations the BSSE effects are negligible at the B3LYP level. They appear to be more relevant for correlated methods. However, the CP-correction to the energy dramatically decreases when using an all-electron basis for the metal atom. For instance, for the $\mathrm{AgCO}^{+}$the contribution from the metal atom to the CP-correction drops to just $0.6 \mathrm{kcal} \mathrm{mol}^{-1}$, to be compared with ca. $3 \mathrm{kcal} \mathrm{mol}^{-1}$ obtained for the same system with the ECP basis.

Geometry optimizations on the CP-corrected potential energy surface and subsequent harmonic frequency calculations with Gaussian indicate that genuinely intramolecular parameters like the carbonyl stretching frequency remain essentially unaffected by BSSE, even at the correlated level. Thus, we expect that in our DC-CCSD(T) benchmark calculations any BSSE effects are likely to be very small in terms of optimized parameters and negligible for carbonyl frequency shifts. Concerning the BSSE correction to
Table 4 Estimated BSSE correction to the bond dissociation energies (in kcal $\mathrm{mol}^{-1}$ )

\begin{tabular}{ll}
\hline System & $\mathrm{CP}^{-\operatorname{correction}^{a}\left(\mathrm{kcal} \mathrm{mol}^{-1}\right)}$ \\
\hline $\mathrm{CuCO}^{+}$ & 2.0 \\
$\mathrm{AgCO}^{+}$ & 0.9 \\
$\mathrm{AuCO}^{+}$ & 1.6 \\
$\mathrm{RgCO}^{+}$ & 2.3 \\
$\mathrm{ZnCO}^{2+}$ & 1.5 \\
$\mathrm{CdCO}^{2+}$ & 1.3 \\
$\mathrm{HgCO}^{2+}$ & 1.2 \\
$\mathrm{CnCO}^{2+}$ & 1.8 \\
${ }^{a}$ See text for details. &
\end{tabular}

the $D_{\mathrm{e}}$ values, it has been estimated as follows. First, we have found in the non-relativistic CP calculations that the major contribution comes from the delocalization from the metal atom to the ghost orbitals of the CO moiety. The reverse contribution (from CO to the ghosts of the metal atom) contributes pretty constantly among the different complexes with less than $0.5 \mathrm{kcal} \mathrm{mol}^{-1}$, both for ECP and the all-electron basis on the metal atom. Another interesting observation is that the CP-correction is essentially the same at MP2 and CCSD levels of theory. Taking all this into account, we have evaluated at the DC-MP2 level the contribution from the metal atom to the CP-correction for each system, whereas the contribution of the CO moiety has been taken as $0.5 \mathrm{kcal} \mathrm{mol}^{-1}$ in all cases. These BSSE estimates are gathered in Table 4.

On the other hand, Table 5 collects the results for a basis set analysis on the bond dissociation energies. We have used uncontracted basis sets of double, triple and up to quadruple zeta on the metal atoms, whenever possible, using the X2C DF, MP2 and CCSD(T) methods. The complete basis set limit (CBS) of the $D_{\mathrm{e}}$ values for each method has been estimated as follows. For the uncorrelated DF energies we have taken the VQZ value; the data in Table 4 show that with such large basis set the $D_{\mathrm{e}}$ values are essentially converged. For the correlation part of the MP2 energies we have used the CBS extrapolation formula ${ }^{42}$

$$
E_{X}=E_{\mathrm{CBS}}+a X^{-3}
$$

where $X$ refers to the cardinal of the basis set (i.e. 2, 3 and 4 for VDZ, VTZ and VQZ, respectively). In principle one could use the data from the VDZ, VTZ and VQZ to get the CBS energy estimates with a least squares fit of the correlation energies to eqn (1). However, since the VDZ energies are typically somewhat far from the CBS limit it is more appropriate to use a two-point extrapolation using the VTZ and VQZ data. Indeed, according to Halkier et $a l^{43}$ the best extrapolations are obtained using twopoint fits with the two largest cardinal numbers. Our computational capabilities prevented us to carry out X2C-CCSD(T)/VQZ calculations. On the other hand, we have observed that the correlation energies at the MP2 and $\operatorname{CCSD}(\mathrm{T})$ levels with VDZ and VTZ basis sets yield quite similar $a$ values using a two-point extrapolation using eqn (1) with the VDZ and VTZ energies. The analysis of the data reported in ref. 43, including larger basis sets, yielded similar conclusions. Thus, the CBS values were estimated from eqn (1) using the $\operatorname{CCSD}(\mathrm{T})$ correlation energies 
Table 5 Basis set evolution and the complete basis set estimate (CBS) of the bond dissociation energies ( $\mathrm{kcal} \mathrm{mol}^{-1}$ ) obtained using two-component methods $(\mathrm{X} 2 \mathrm{C})$

\begin{tabular}{|c|c|c|c|c|}
\hline & VDZ & VTZ & VQZ & CBS \\
\hline \multicolumn{5}{|l|}{$\mathrm{AgCO}^{+}$} \\
\hline DF & 11.5 & 11.6 & 11.5 & 11.5 \\
\hline MP2 & 26.9 & 28.7 & 30.2 & 31.3 \\
\hline $\operatorname{CCSD}(\mathrm{T})$ & 23.9 & 25.0 & - & $27.7^{a}$ \\
\hline \multicolumn{5}{|l|}{$\mathrm{AuCO}^{+}$} \\
\hline DF & 22.3 & 22.6 & 22.5 & 22.5 \\
\hline MP2 & 56.3 & 59.3 & 60.0 & 60.5 \\
\hline $\operatorname{CCSD}(\mathrm{T})$ & 49.2 & 51.0 & - & $52.1^{a}$ \\
\hline \multicolumn{5}{|l|}{$\mathrm{RgCO}^{+}$} \\
\hline $\mathrm{DF}$ & 113.7 & 118.3 & 118.5 & 118.5 \\
\hline MP2 & 174.3 & 177.5 & 179.7 & 181.0 \\
\hline $\operatorname{CCSD}(\mathrm{T})$ & 108.4 & 126.8 & - & $130.0^{a}$ \\
\hline \multicolumn{5}{|l|}{$\mathrm{CdCO}^{2+}$} \\
\hline DF & 42.5 & 43.1 & 43.1 & 43.1 \\
\hline MP2 & 62.2 & 64.4 & 64.9 & 65.2 \\
\hline $\operatorname{CCSD}(\mathrm{T})$ & 59.2 & 61.1 & - & $61.8^{a}$ \\
\hline \multicolumn{5}{|l|}{$\mathrm{HgCO}^{2+}$} \\
\hline $\mathrm{DF}$ & 53.5 & 53.9 & 53.9 & 53.9 \\
\hline MP2 & 84.0 & 86.5 & 87.2 & 87.7 \\
\hline $\operatorname{CCSD}(\mathrm{T})$ & 79.6 & 81.4 & - & $82.4^{a}$ \\
\hline \multicolumn{5}{|l|}{$\mathrm{CnCO}^{2+}$} \\
\hline $\mathrm{DF}$ & 130.2 & 134.1 & 134.3 & 134.3 \\
\hline MP2 & 190.6 & 194.4 & 199.3 & 202.6 \\
\hline $\operatorname{CCSD}(\mathrm{T})$ & 167.8 & 172.0 & - & $180.1^{a}$ \\
\hline
\end{tabular}

with the VTZ basis and the $a$ parameter was obtained in the two-point extrapolation process of the MP2 correlation energies using VTZ and VQZ basis sets. The CBS extrapolated $D_{\mathrm{e}}$ values should be within $1 \mathrm{kcal} \mathrm{mol}^{-1}$ error.

Finally, it is interesting to analyze the electronic structure of these metal carbonyl compounds, particularly how the relativistic corrections affect the electron distribution. Unfortunately, the number of bonding analyses that can be carried with fourcomponent calculations is quite limited,${ }^{44}$ and since the bonding mechanism for these species has been broadly studied in the past, ${ }^{10-12,45}$ here we will mostly focus on the relativistic effects upon the electron density.

To this aim, we have plotted in Fig. 4 the density difference between DC-DF and LL-DF calculations at the DC-CCSD(T) optimized geometries of all systems along the plane containing the three atoms. The correlation effects on the electron density in the bonding regions are usually quite small and the relativistic corrections are often quite independent of the method itself, so we expect our results to be qualitatively valid. ${ }^{46}$ It is well known that relativistic effects contract the innermost shells, causing an effective better shielding that expands the next shell. This effect repeats several times if there are several d-shells occupied. As a result, we can appreciate the shell structure of the TM in the density difference plots: the larger the TM, the more shells we can observe. The four-component methods report larger density close to the nuclei and, as a result, the density is smaller in the closest region. The effect on the complexes with the lightest TMs is only notorious close to the metal itself and the effect on $\mathrm{C}-\mathrm{O}$ bonding is noticeable for the third- and fourth-row carbonyl complexes.

In order to properly quantify the density changes we have computed the bond critical points (BCPs), i.e. the minimum density points along the interatomic axis. ${ }^{34}$ There are two BCPs in each system, one between the $\mathrm{C}$ and $\mathrm{O}$ atoms and another between the metal $(\mathrm{M})$ and the $\mathrm{C}$ atom. The displacement of the former due to relativistic effects is negligible and we thus only report the data for the $\mathrm{M}-\mathrm{C}$ BCPs in Table 6. The position of the M-C BCP is only slightly affected by the relativistic treatment and thus we have only included the BCP position of the fourcomponent calculation in Fig. 4. The position of the BCP can be used as a rough estimate of the atomic boundaries within the molecule. The atomic radius of the TM within the complex is contracted up to $5 \%$ and the value of the density at the BCP increases up to $13 \%$ upon introduction of relativistic effects. The density along the $\mathrm{C}-\mathrm{O}$ bond path is displaced towards the perpendicular region close to $\mathrm{C}$ and $\mathrm{O}$ nuclei and the $\mathrm{M}-\mathrm{C}$ bond density experiences a shift towards the TM. In general, the relativistic effects move electron density from $\mathrm{O}$ and $\mathrm{C}$, and particularly from the $\mathrm{C}$ atom towards the transition metal. This increase of the electron density in the interatomic region between the metal and the carbonyl conforms to the increase of covalent character of the bonding interaction going down the group due to relativistic effects.

Finally, the bonding mechanism between the TM atom, M, and the $\mathrm{CO}$ molecule has been explored by population analysis of the relevant individual orbitals of the complexes. The extent of $\sigma$-donation can be identified as the difference between the number of electrons on sigma orbitals on the free CO moiety (10) and the sum of the Mulliken populations of the sigma orbitals of the complex on $\mathrm{C}$ and $\mathrm{O}$ atomic orbitals. Positive values of $\sigma$-donation indicate that sigma electrons have flown from the CO moiety to the TM atom. Similarly, the $\pi$-backdonation is quantified as the difference between the sum of the Mulliken populations of the $\pi$ orbitals of the complex on C and O AO's and the number of $\pi$ electrons on free $\mathrm{CO}(4)$. Positive values of $\pi$-backdonation indicate that electrons have flown from the TM atom to the $\pi$ system of the CO moiety. It is worth mentioning that in the relativistic formalism the $\sigma$ and $\pi$ contributions mix to some extent, depending upon the magnitude of the spinorbit splitting of atomic orbitals involved in the bond. Hence, the Dewar-Chatt-Duncanson picture of the bonding between the metal atom and the CO moiety may get blurred going down in the group. This problem was well described for diatomic molecules with bonds involving p orbitals. ${ }^{21,47-49}$ However, in the systems considered in this work, the $\mathrm{d}$ valence atomic orbitals are the ones involved in the bonding mechanism, for which the magnitude of spin-orbit splitting is at least one order of magnitude smaller than the spin-orbit splitting of corresponding valence $\mathrm{p}$ orbitals. Therefore we can assume that, to a good approximation, the bonding orbitals mostly preserve their predominant $\sigma$ and $\pi$ character.

In Table 7 we have collected the two contributions of the bonding mechanism for DC and LL calculations. Direct comparison 


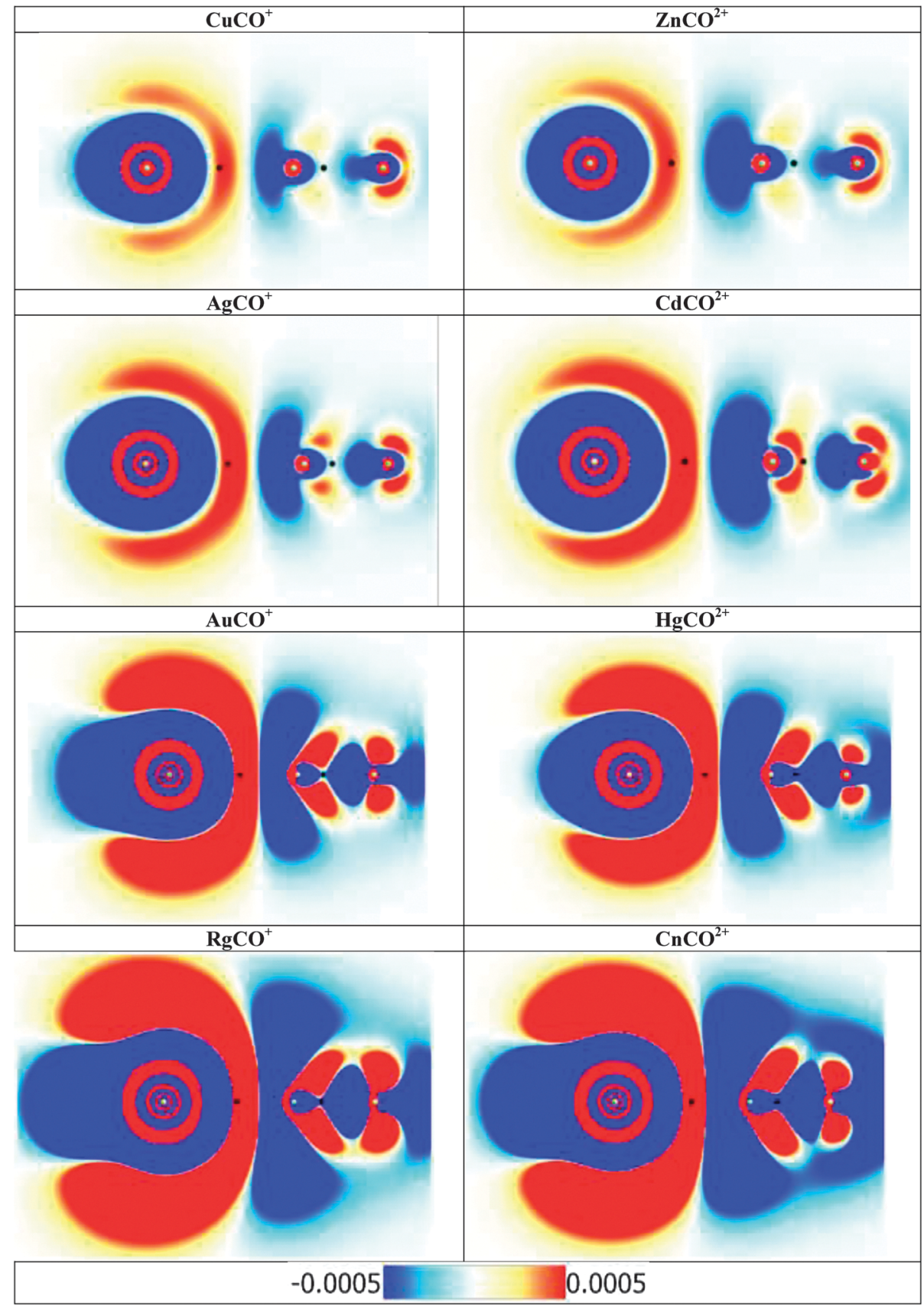

Fig. 42 2D density plot difference between DC-DF and LL-DF calculations at the DC-CCSD(T) geometries. The black dots represent the bond critical point position according to DC-DF calculation. Green spheres indicate atomic positions.

Table 6 Position (distance with respect to the metal atom, in $\AA$ ) and the electron density value (a.u.) of the M-C bond critical points of the metal-carbonyl complexes at the Dirac-Fock level using both Dirac-Coulomb (DC) and Lévy-Leblond (LL) Hamiltonians. The last two rows collect the percentage deviation with respect to the four-component values

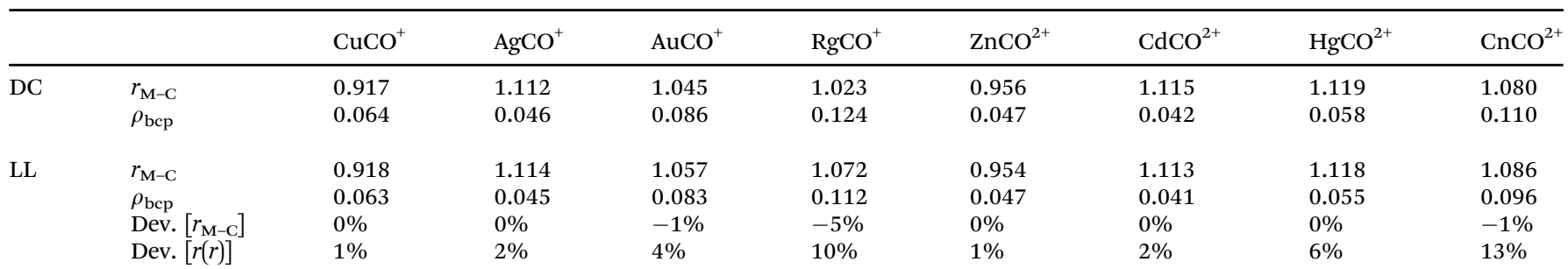


Table $7 \sigma$-Donation and $\pi$-backdonation of the carbonyl complexes estimated from gross populations calculated at the Dirac-Fock level using both Dirac-Coulomb (DC) and Lévy-Leblond (LL) Hamiltonians

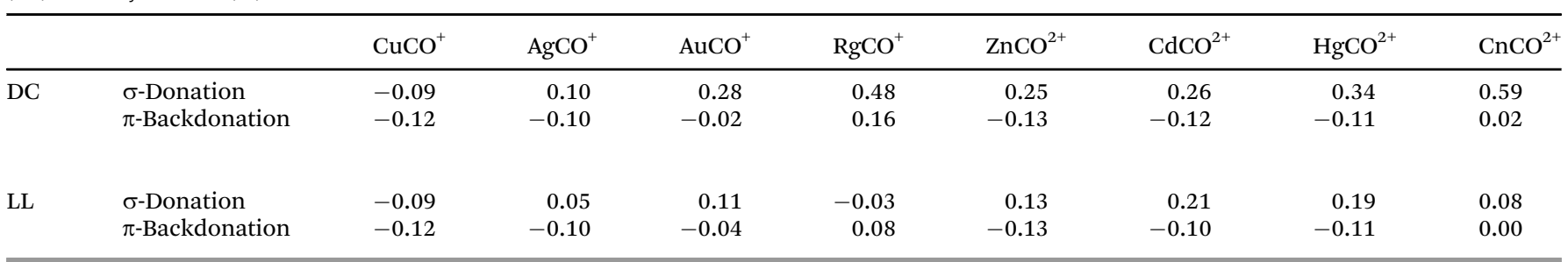

of the data between the two methods provides quantification of the relativistic effects upon the bonding. The effect of $\sigma$-donation increases significantly when going down in the group, especially on the transition from the third to the fourth row. However, this fact is severely underestimated by the Lévy-Leblonde method, thus putting forward the need of relativistic corrections to account for this effect. The enhanced effect of $\sigma$-donation on fourth-row carbonyl complexes is highlighted by the strengthening of the $\mathrm{M}-\mathrm{C}$ bond, as demonstrated by the large $D_{\mathrm{e}}$ values, and the increase in the stretching frequency of the carbonyl group. $\pi$-backdonation, on the other hand, slightly increases down the group, in agreement with the small increase observed in the C-O distance. It increases more significantly for the fourth-row carbonyl complexes, indicating an overall enhancement of the bonding interaction between the TM and CO. Interestingly, the role of $\pi$-backdonation seems to be quite well estimated with a non-relativistic density.

\section{Conclusions}

In this paper we present benchmark results for metal carbonyl complexes of the groups 11 and 12 of the periodic table. The focus is on the geometry, vibrational frequencies, bond dissociation energy and relativistic effects on the bonding mechanism. The correct description of these complexes requires a balanced account of electron correlation and relativistic effects. Our results demonstrate that the combination of the effective core potential and the MP2 method gives quantitative results for the first- and the secondrow TM complexes and only qualitative agreement for the thirdrow complexes. The fourth-row TM carbonyl complexes from groups 11 and 12 have been studied for the first time.

The relativistic corrections grow with the atomic number of the metal atom and are responsible for the $\mathrm{M}-\mathrm{C}$ bond length contraction, the decrease of $\mathrm{M}-\mathrm{C}$ stretching and the increase of the bond dissociation energy. These effects are not negligible for complexes with first and second row TM atoms and are huge for molecules with heavy and superheavy elements. The relativistic corrections on the CO vibrational frequency and the bond dissociation energy are as large as $380 \mathrm{~cm}^{-1}$ and $140 \mathrm{kcal} \mathrm{mol}^{-1}$, thus indicating that the inclusion of relativistic effects is mandatory for these complexes. X2C methods give dissociation energies, geometries and CO stretching frequencies in close agreement with Dirac-Coulomb results. Only a few bending frequencies are wrongly estimated with this two-component method.

Finally, the relativistic effects on the bonding have also been studied by means of electron density difference maps and bond critical point features and differences in the quantification of the $\sigma$-donation and $\pi$-backdonation effects. The relativistic effects shrink the size of the metal within the molecule and displace the electron density from the CO fragment towards the metal. They also significantly increase the $\sigma$-donation of the CO to the TM, thus enhancing the covalent character of the $\mathrm{M}-\mathrm{C}$ bond.

\section{Acknowledgements}

We would like to thank Dr Georg Eickerling and Prof. Scherer's for providing a Mathematica script to analyze the topology of the density. Financial help has been furnished by the Polish Ministry of Science and Higher Education (project no. N N204 215634), the Spanish MICINN (project no. CTQ2011-23156/BQU and CTQ2011-23441/BQU) and by the FEDER fund (European Fund for Regional Development; grant UNGI08-4E-003). Financial support from the Generalitat de Catalunya (SGR637 and Xarxa de Referència en Química Teòrica i Computacional) is also acknowledged. E.M. acknowledges financial support from the EU under Marie Curie Career Integration grant (PCI09-GA-2011-294240) and the Beatriu de Pinós program from AGAUR for the postdoctoral grant (BP_B_00236). Most calculations reported in this paper have been performed in our (University of Szczecin) server SUN Fire X4400. We would like to thank K. Dyall for providing us with the VTZ basis sets for $\mathrm{Cu}$ and $\mathrm{Zn}$ elements.

\section{References}

1 S. H. Strauss, Chem. Rev., 1993, 93, 927.

2 S. H. Strauss, Chemtracts: Inorg. Chem., 1997, 10, 77.

3 A. J. Lupinetti, V. Jonas, W. Thiel, S. H. Strauss and G. Frenking, Chem.-Eur. J., 1999, 5, 2573.

4 A. J. Lupinetti, G. Frenking and S. H. Strauss, Angew. Chem., Int. Ed., 1998, 37, 2113.

5 A. J. Lupinetti, S. Fau, G. Frenking and S. H. Strauss, J. Phys. Chem. A, 1997, 101, 9551.

6 P. K. Hurlburt, J. J. Rack, J. S. Luck, S. F. Dec, J. D. Webb, O. P. Anderson and S. H. Strauss, J. Am. Chem. Soc., 1994, 116, 10003.

7 F. Meyer, Y.-M. Chen and P. B. Armentrout, J. Am. Chem. Soc., 1995, 117, 4071.

8 M. Bodenbinder, G. Balzer-Jollenbeck, H. Willner, R. J. Batchelor, F. W. B. Einstein, C. Wang and F. Aubke, Inorg. Chem., 1996, 35, 82.

9 R. Kuster and K. Seppelt, Z. Anorg. Allg. Chem., 2000, 626, 236. 10 M. J. S. Dewar, Bull. Soc. Chim. Fr., 1951, 18, C79. 
11 J. Chatt and J. S. Duncanson, J. Chem. Soc., 1953, 2939.

12 G. Frenking and N. Frohlich, Chem. Rev., 2000, 100, 717.

13 D. C. Hoffman, D. M. Lee and V. Pershina, Transactinide Elements and Future Elements, in The Chemistry of the Actinide and Transactinide Elements, ed. L. R. Morss, N. M. Edelstein and J. Fuger, Springer Netherlands, 2011, p. 1652.

14 E. Eliav, U. Kaldor, P. Schwerdtfeger, B. A. Hess and Y. Ishikawa, Phys. Rev. Lett., 1994, 73, 3203.

15 E. Eliav, U. Kaldorand and Y. Ishikawa, Phys. Rev. A, 1995, 52, 2765.

16 M. Schädel, Angew. Chem., Int. Ed., 2006, 45, 368.

17 J. Karwowski, Quantum-Chemical Models, in Problem Solving in Computational Molecular Science, ed. S. Wilson and G. H. F. Dierksen, Kluwer Academic Publisher, Dorderecht, 1997.

18 K. G. Dyall and K. Fægri Jr., Introduction to Relativistic Quantum Chemistry, Oxford University Press, 2007.

19 M. Barysz and A. J. Sadlej, J. Chem. Phys., 2002, 116, 2696.

20 D. Peng and M. Reiher, Theor. Chem. Acc., 2012, 131, 1081.

21 K. Fægri and T. Saue, J. Chem. Phys., 2001, 115, 2456.

22 R. Bast, H. J. A. Jensen, T. Saue, L. Visscher, with contributions from, V. Bakken, K. G. Dyall, S. Dubillard, U. Ekström, E. Eliav, T. Enevoldsen, T. Fleig, O. Fossgaard, A. S. P. Gomes, T. Helgaker, J. K. Lærdahl, J. Henriksson, M. Iliaš, C. R. Jacob, S. Knecht, C. V. Larsen, H. S. Nataraj, P. Norman, G. Olejniczak, J. Olsen, J. K. Pedersen, M. Pernpointner, K. Ruud, P. Sałek, B. Schimmelpfennig, J. Sikkema, A. J. Thorvaldsen, J. Thyssen, J. v. Stralen, S. Villaume, O. Visser, T. Winther, S. Yamamoto, DIRAC, a relativistic $a b$ initio electronic structure program, Release DIRAC11, 2011.

23 K. G. Dyall, Theor. Chem. Acc., 2004, 112, 403.

24 K. G. Dyall, Theor. Chem. Acc., 2007, 117, 483.

25 K. G. Dyall, Theor. Chem. Acc., 2011, 129, 603.

26 K. G. Dyall and A. S. P. Gomes, Theor. Chem. Acc., 2010, 125, 97.

27 T. H. Dunning, J. Chem. Phys., 1989, 90, 1007.

28 L. Visscher, K. G. Dyall, http://www.chem.vu.nl/ visscher/ FiniteNuclei/FiniteNuclei.htm, 1997.

29 M. J. Frisch, G. W. Trucks, H. B. Schlegel, G. E. Scuseria, M. A. Robb, J. R. Cheeseman, G. Scalmani, V. Barone, B. Mennucci, G. A. Petersson, H. Nakatsuji, M. Caricato, X. Li, H. P. Hratchian, A. F. Izmaylov, J. Bloino, G. Zheng, J. L. Sonnenberg, M. Hada, M. Ehara, K. Toyota, R. Fukuda, J. Hasegawa, M. Ishida, T. Nakajima, Y. Honda, O. Kitao, H. Nakai, T. Vreven, J. J. A. Montgomery, J. E. Peralta, F. Ogliaro, M. Bearpark, J. J. Heyd, E. Brothers,
K. N. Kudin, V. N. Staroverov, R. Kobayashi, J. Normand, K. Raghavachari, A. Rendell, J. C. Burant, S. S. Iyengar, J. Tomasi, M. Cossi, N. Rega, J. M. Millam, M. Klene, J. E. Knox, J. B. Cross, V. Bakken, C. Adamo, J. Jaramillo, R. Gomperts, R. E. Stratmann, O. Yazyev, A. J. Austin, R. Cammi, C. Pomelli, J. W. Ochterski, R. L. Martin, K. Morokuma, V. G. Zakrzewski, G. A. Voth, P. Salvador, J. J. Dannenberg, S. Dapprich, A. D. Daniels, Ö. Farkas, J. B. Foresman, J. V. Ortiz, J. Cioslowski and D. J. Fox, Gaussian 09, Revision A.02, Gaussian, Inc., 2009.

30 D. Figgen, G. Rauhut, M. Dolg and H. Stoll, Chem. Phys., 2005, 311, 227.

31 D. Andrae, U. Haeussermann, M. Dolg, H. Stoll and H. Preuss, Theor. Chim. Acta, 1990, 77, 123.

32 Ö. Farkas and H. B. Schlegel, Phys. Chem. Chem. Phys., 2002, 4, 11.

33 L. Visscher, Theor. Chem. Acc., 1997, 98, 68.

34 R. F. W. Bader, Atoms in Molecules. A Quantum Theory, Oxford University Press, Oxford, 1990.

35 M. Presnitz, F. Mayer, V. Herz, G. Eickerling, W. Scherer, Mathematica Script for the Processing of Volume Data (Calculation of the Laplacian Field), Universität Augsburg (Lehrstuhl CPM), 2007.

36 M. Zhou and L. Andrews, J. Chem. Phys., 1999, 111, 4548.

37 M. P. Johansson and P. Pyykkö, Chem. Commun., 2010, 46, 3762.

38 P. Pyykkö, Annu. Rev. Phys. Chem., 2012, 63, 45.

39 J. Autschbach, J. Chem. Phys., 2012, 136, 150902.

40 K. S. Pitzer, Acc. Chem. Res., 1979, 12, 271.

41 S. F. Boys and F. Bernardi, Mol. Phys., 1970, 19, 553.

42 T. Helgaker, W. Klopper, H. Koch and J. Noga, J. Chem. Phys., 1997, 106, 9639.

43 A. Halkier, T. Helgaker, P. Jørgensen, W. Klopper, H. Koch, J. Olsen and A. K. Wilson, Chem. Phys. Lett., 1998, 286, 243. 44 G. Eickerling, R. Mastalerz, V. Herz, W. Scherer, H.-J. Himmel and M. Reiher, J. Chem. Theory Comput., 2007, 3, 2182.

45 J. Pilme, B. Silvi and M. E. Alikhani, J. Phys. Chem. A, 2003, 107, 4506.

46 E. Matito and M. Sola, Coord. Chem. Rev., 2009, 253, 647.

47 T. Saue, K. Fægri and O. Gropen, Chem. Phys. Lett., 1996, 263, 360.

48 L. Visscher, J. Styszynski and W. C. Nieuwpoort, J. Chem. Phys., 1996, 105, 1987.

49 O. Fossgaard, O. Gropen, E. Eliav and T. Saue, J. Chem. Phys., 2003, 119, 9355.

50 B. Liang and L. Andrews, J. Phys. Chem. A, 2000, 104, 9156. 